\title{
La utilización de recursos escasos en telecomunicaciones: el caso del espectro radioeléctrico y la numeración
}

\author{
Diego Zegarra Valdivia
}

\section{Introducción}

La oferta de un conjunto de servicios vinculados a la actividad de telecomunicaciones involucra la instalación de fibra óptica, antenas, cableado, etc., es decir, toda la infraestructura y equipos de los que son necesarios disponer. Todo ello está estrechamente vinculado con el uso del dominio público (sea espacial o terrestre) o de otro tipo de recursos sobre los cuales podrán darse habilitaciones administrativas para su uso privativo, con el fin de favorecer el despliegue tecnológico que sea necesario y de que se garantice la operatividad del servicio público de telecomunicaciones.

Los operadores de telecomunicaciones tienen la posibilidad de ejercer una serie de derechos de uso de aquellos recursos que son indispensables para el desarrollo de la actividad. El ejercicio de estos derechos está vinculado con una serie de obligaciones establecidas vía ley, cuya supervisión se encuentra a cargo de la Administración sectorial, la cual está en calidad de titular de los bienes que son afectados al uso, por ser ella quien ejerce competencias en la gestión de dichos recursos.

Sobre la base de las consideraciones generales antes expuestas, se ha planteado, como objetivo del presente trabajo, el estudio de los principales aspectos jurídicos vinculados a la utilización de recursos, como el espectro radio eléctrico y la numeración en la actividad de las telecomunicaciones, así como de las implicancias que derivan de su carácter escaso, que hacen

Doctor en Derecho por la Universidad de Alicante. Master en Derecho de las Telecomunicaciones y de las Tecnologías de la Información por la Universidad Carlos III de Madrid. Especialista en Derecho de la Competencia de la Unión Europea. Profesor ordinario de la Pontificia Universidad Católica del Perú. 
indispensable su racionalización por parte de la Administración sectorial, y que se traducen en la necesaria garantía del uso eficiente de los mismos y la igualdad de su aprovechamiento.

\section{El espectro radioeléctrico}

\section{Consideraciones generales}

Una gran parte de los servicios de telecomunicaciones que se prestan requiere el uso de ondas radioeléctricas como vehículo de transmisión de las comunicaciones. Así, dentro del género telecomunicaciones, se sitúa una especie de servicios en particular que integran las radiocomunicaciones. ${ }^{1}$ "Se trata básicamente de sistemas de transmisión mediante microondas que utilizan el espectro radioeléctrico en mayor o menor medida». ${ }^{2}$

Técnicamente, el espectro radioeléctrico es el espacio donde se propagan las ondas radioeléctricas; en este sentido, se define como aquella parte del espectro electromagnético que abarca desde los 9 kilohertzios hasta los 3.000 gigahertzios y cuya utilización para aplicaciones de radiocomunicaciones está regulada por acuerdos internacionales celebrados en el marco de la Unión Internacional de Telecomunicaciones, ${ }^{3}$ lo que significa que la legislación interna del Perú se encuentra sometida a esta normativa internacional.

La Ley de Telecomunicaciones peruana (en adelante LTel) ${ }^{4}$ define el espectro radioeléctrico como un «recurso natural de dimensiones limitadas que forma parte del patrimonio de la Nación».5 Se trata, entonces, de un

Molina, A. Las antenas de telefonía móvil. Su régimen jurídico. Navarra: Aranzadi, 2002, p. 57.

2 Ib. Como precisa el autor, en estos sistemas se presentan tanto los servicios de difusión punto-multipunto como los servicios bidireccionales punto-punto.

3 SANCHez BLANCO, M. "La regulación del uso del espectro radioeléctrico». En J. Cremades (coord.). Derecho de las Telecomunicaciones. Madrid: La Ley-Actualidad-Ministerio de Fomento, 1997, p. 796.

4 Decreto supremo 013-93-TCC, de 28 de abril de 1993, Texto Único Ordenado de la Ley de Telecomunicaciones.

5 Al respecto, véase el artículo 57 de la LTel y el artículo 206 del decreto supremo 027-2004MTC, de 9 de julio de 2004, Texto Único Ordenado del Reglamento General de la Ley de Telecomunicaciones (en adelante Riel). Al igual que la derogada ley 11/1998, Ley General de Telecomunicaciones española, la LTel no establece el objeto del espectro radioeléctrico (objeto de demanio); sin embargo, en las definiciones del Plan Nacional de Atribución de Frecuencias (PNAF), aprobado por resolución ministerial 187-2005-MTC-03, de 1 de abril de 2005, se establece: 
recurso natural escaso en la medida en que las posibilidades de ocupación de este son limitadas. ${ }^{6}$ Esta característica se ve acentuada por dos circunstancias. Por un lado, el hecho de que cada frecuencia presente unas propiedades físicas (ancho de banda, atenuación de señal, etc.) supone que determinadas bandas de frecuencias solo puedan ser utilizadas para servicios concretos y que pueda generarse una gran demanda de distintos servicios para ocupar una misma banda. ${ }^{7}$

Por otro lado, los avances tecnológicos han hecho que los servicios dependientes del uso del espectro radioeléctrico se hayan multiplicado, ${ }^{8} \mathrm{de}$ forma que el aumento de capacidad del espectro es directamente proporcional con un aumento del uso del mismo. ${ }^{9}$

Ante la escasez del espectro radioeléctrico —agravada por la especificidad de determinadas bandas para el uso de ciertos servicios y la demanda cada vez mayor de servicios que se basan en el uso del espectro-, cobra gran relevancia su regulación y planificación, y, como veremos más adelante, el uso racional y eficiente del espectro radioeléctrico y de la asignación de frecuencias dependerá de la capacidad de la Administración sectorial para ordenarlo y gestionarlo. ${ }^{10}$

Por este motivo, es necesario que exista una coordinación internacional sobre el uso del espectro, coordinación que es llevada a cabo por la Unión Internacional de Telecomunicaciones (UIT). ${ }^{11}$ Dicho organismo elaboró, a modo de principal instrumento de regulación, el Reglamento de Radiocomunicaciones (Ginebra, 6 de diciembre de 1979), cuya revisión y actualización es

"Artículo I. Términos y definiciones. Sección I.

Términos generales [...]

1.4 Ondas radioeléctricas u Ondas Hertzianas: Ondas electromagnéticas, cuya frecuencia se fija convencionalmente por debajo de $3000 \mathrm{GHz}$ que se propagan por el espacio sin guía artificial».

6 MOLINA, A. Op. cit., pp. 57-58.

7 MARZO, J. "El dominio público radioeléctrico». En C. Chinchilla (coord.). Telecomunicaciones: Estudios sobre Dominio Público y Propiedad Privada. Madrid: Marcial Pons, 2000, p. 151.

$8 \mathrm{lb}$

9 TORRES, M. A. Las comunicaciones móviles y su régimen jurídico. Especial tratamiento de la telefonía móvil. Madrid: Civitas, p. 146.

10 En este punto, seguimos el planteamiento de MARZO, J. Op. cit., pp. 151-152; en esta misma línea, véase SANCHEZ BLANCO, M. Op. cit., pp. 798-799.

1 Como precisa SANChez BLANCO, M. Op. cit., p. 816, "con objeto de facilitar la cooperación internacional en materia de telecomunicaciones, los países participantes en la Conferencia de Madrid de 1932, decidieron crear una organización internacional única a la que se le dio el nombre de Unión Internacional de Telecomunicaciones (UIT), regulada por un único Convenio Internacional de Telecomunicaciones, complementado por los reglamentos Telegráfico, Telefónico y de Radiocomunicaciones». 
permanente en el seno de la UIT por medio de las conferencias de las radiocomunicaciones, en las que se revisan el Reglamento y cualquiera de los planes correspondientes (frecuencias). ${ }^{12}$

\section{Sobre la naturaleza demanial del espectro radio eléctrico}

En lo que respecta a la naturaleza demanial del espectro radioeléctrico, esta llama la atención, ya que no deja de ser anómala en la medida que el aire en sí mismo no es dominio público, sino el soporte de las ondas; sin embargo, pueden existir distintas razones por las cuales el espectro radioeléctrico tiene carácter demanial.

En su momento, como sostiene Fernando Pablo, «la necesidad de proclamar la llamada "demanialización herziana» fue sentida por el socialismo francés como medio de retener las necesarias potestades públicas para ordenar un panorama audiovisual en constante cambio». ${ }^{13}$

Para Chinchilla,

[...] superada la concepción clásica del demanio que lo identificaba exclusivamente con el título de propiedad hay que concluir que si bien la extravagancia del objeto —refiriéndose al espectro radioeléctrico—impide considerarlo como una propiedad del Estado, nada se opone a que venga definido como una zona de competencia demanial del mismo, en el sentido de título de intervención con el que el Estado pretende garantizar un uso ordenado y eficaz del bien. ${ }^{14}$

En el caso del Perú, podemos entender, desde un punto de vista dogmático, que la racionalidad de la demanialización del recurso tiene que ver con la configuración de potestades de intervención de la Administración sectorial, lo que supone, además, que se pueda cumplir con la finalidad de que dichas potestades sean utilizadas para que se sirva con utilidad los intereses generales. ${ }^{15}$

12 Al respecto, véase SANCHEZ BLANCO, M. Op. cit., p. 816.

13 Fernando Pablo, M. M. "Dominio Público Radioeléctrico» En E. Garcia de Enterria y T. de la Quadra (coords.). Comentarios a la Ley General de Telecomunicaciones. Madrid: Civitas, 1999, p. 535.

14 Chinchilla, C. La radio-televisión como servicio público esencial. Madrid: Tecnos, 1988, p. 141.

15 En este punto, seguimos el planteamiento de GONZALEZ, J. V. La titularidad de los bienes del dominio público. Madrid, Barcelona: Marcial Pons, 1998, p. 58; véase también SANZ MORENO, F. "El dominio público: una reflexión sobre su concepto y naturaleza, cincuenta años después de la fundación de la "Revista de Administración Pública"». Revista de Administración Pública, n. ${ }^{\circ}$ 150, septiembre-diciembre, 1999, pp. 477-514. 
Asimismo, con la publificación de espectro radioeléctrico, la Administración asume competencias de obligado ejercicio que tienden a la protección del mismo ${ }^{16}$ y cuya finalidad radica en preservar su existencia, disponibilidad y el servicio que con él se presta a la satisfacción de los intereses generales. ${ }^{17}$ En esta línea, el artículo 57 de la LTel ha dispuesto que la administración y gestión del espectro radioeléctrico corresponda al Ministerio de Transportes y Comunicaciones (en adelante MTC); para ello, este organismo deberá atenerse no solo a la normativa sectorial nacional, sino también a las normas de ámbito internacional, «lo cual es absolutamente necesario debido a la especial naturaleza del espectro, que no respeta las fronteras nacionales y no admite límite alguno». ${ }^{18}$

En el ámbito de la Unión Europea, ${ }^{19}$ la reciente decisión 676/2002/ CE, de 7 de marzo de 2002, sobre un marco regulador de la política de espectro radioeléctrico en la Comunidad Europea (Decisión Espectro Radioeléctrico), definió el espectro radioeléctrico como «las ondas radioeléctricas en las frecuencias comprendidas entre 9 Khz. y $3000 \mathrm{GHz}$; las ondas radioeléctricas son ondas electromagnéticas propagadas por el espacio sin guía artificial». ${ }^{20}$

En el caso de España, con la ley 32/2003, Ley General de Telecomunicaciones, si bien se traspuso la Decisión Espectro Radioeléctrico, en opinión de Calvo y Sanmartin, ${ }^{21}$ se buscó, además, solventar aquellos problemas

16 En este mismo sentido, véase Molina, A. op. cit., p. 59.

17 Hemos adecuado el planteamiento de PAREJO ALFONSO, L. "Domino público: un ensayo de reconstrucción de su teoría general». Revista de Administración Pública, n. ${ }^{\text {s }} 100$ 102, p. 2379 y ss. al carácter escaso del espectro radioeléctrico.

18 Calvo, A. y J. SANmartin. "Artículo 43.- Gestión del Dominio Público Radioeléctrico». En J. Cremades y J. Rodriguez-Arana (dirs.). Comentarios a la Ley General de Telecomunicaciones. Madrid: La Ley, 2004, p. 582.

19 Como se precisa en GRETEL. Nuevo Diseño Europeo de las Telecomunicaciones, el Audiovisual e Internet. Madrid: Colegio Oficial de Ingenieros de Telecomunicación, 2002, p. 250, "el interés por una regulación del espectro radioeléctrico en el ámbito comunitario es reciente. Hasta el año 98 en que se publica el Libro Verde sobre Política de Frecuencias, la regulación europea se centra en el impulso de decisiones ligadas al desarrollo de servicios en el contexto de creación de un mercado paneuropeo de servicios de telecomunicaciones que sirviese al mismo tiempo para el fortalecimiento de la industria europea del sector. Es a partir del año 98 cuando, en el ámbito de la liberalización plena iniciada en enero de ese año, el espectro radioeléctrico cobra mayor importancia, al configurarse como el único recurso capaz de determinar limitaciones en el número de licencias que pueden concederse para el desarrollo de determinadas redes y servicios, a la vez que usuarios y operadores incrementan sus peticiones y necesidades sobre servicios de telecomunicaciones vía radio».

20 Al respecto, véase el artículo 2 de la Decisión Espectro Radioeléctrico.

21 Calvo, A. y J. SANMARTin. Op. cit., p. 580. 
dogmáticos de los que adolecía la anterior $\operatorname{ley}^{22}$ (derivados tanto de la titularidad del dominio radioeléctrico como de su objeto) al establecerse, de forma expresa, que el Estado es el titular del espectro radioeléctrico y al considerar que este es un bien de dominio público, así como también al fijar como su objeto las ondas radioeléctricas emitidas en determinadas frecuencias. ${ }^{23}$

Laguna de Paz realiza un interesante cuestionamiento de la demanilización del espectro radioeléctrico en el contexto actual de liberalización de los servicios de telecomunicaciones en el ámbito de la Unión Europea. Al respecto, el citado autor considera que, si bien el dominio público garantiza una protección particularmente intensa del bien así como su afectación al uso o servicio público, excluyéndola del tráfico privado ordinario, sin embargo, el legislador puede prescindir del dominio público para buscar títulos de intervención como se hacía antes y «reconocer el carácter de res communis omnium del espectro radioeléctrico y, al mismo tiempo, poner en manos de la Administración cuantas potestades sean precisas para la regulación y ordenación del recurso y a sus aprovechamientos». ${ }^{24}$

Ya Fernando Pablo había sostenido, en el caso español, que «el título que justifica la intervención estatal en el espectro de frecuencias no era el dominio público, sino que se trataba de una reserva derivada del artículo 128 de la Constitución española, consistente en la competencia exclusiva sobre la adjudicación de las frecuencias, sin que ello conlleve su demanialización» ${ }^{25}$

En la línea del planteamiento expuesto, coincidimos con Laguna de Paz que existe una serie de presupuestos mínimos que deben ser observados en cuanto a la ordenación normativa del espectro radioeléctrico: ${ }^{26}$

- Debe favorecerse, hasta donde lo permitan las condiciones económicas, de salud, seguridad y sociales, su uso libre, no sujeto a autorización administrativa previa.

- La planificación del uso del espectro radioeléctrico debe estar sometida a permanente revisión — sin por ello descartar cambios en la asignación

22 Véase FERNANDO PABLO, M. M. Op. cit., p. 533-540.

23 Al respecto, véase el artículo 43.1 de la ley 32/2003. Lo cierto es que ya la sentencia del Tribunal Constitucional español 12/1982, de 31 de marzo (RTC 1982, 12) había declarado, pese a la inexistencia de una publicatio legal sobre el espacio radioeléctrico, su carácter demanial.

24 LAGUna de PAZ, J. C. Telecomunicaciones: Regulación y Mercado. Navarra: Aranzadi, 2004, p. 113; en este mismo sentido, véase ARIÑO, G. El proyecto de ley sobre televisión privada. Madrid: IEE, 1987, p. 105.

25 Fernando Pablo, M. M. "Sobre dominio público radioeléctrico: espejismo y realidad». En Revista de Administración Pública, n. ${ }^{\circ}$ 143, mayo-agosto, 1997, pp. 107-147.

26 LAGUNA DE PAZ, J. C. Op. cit., p. 114. 
de frecuencias - para, de esa manera, garantizar una eficiente distribución de usos.

- Hay que respetar la garantía patrimonial de las concesiones o autorizaciones demaniales, ya que dicha estabilidad es la seguridad jurídica que los operadores requieren para seguir efectuando inversiones en el sector.

- Se debe considerar la ordenación del espectro radioeléctrico dentro de su carácter instrumental, para que su razón de ser sea garantizar la disponibilidad de frecuencias para los distintos tipos de servicios y su plena operatividad, mas no buscar ingresos financieros.

Finalmente, dentro del marco de las disposiciones generales de la ley $32 / 2003$, se ha establecido que la competencia respecto de la administración, gestión, planificación y control del espectro radio eléctrico - a diferencia de lo que ocurre en el Perú - no es exclusiva del Ministerio del sector, sino que, además del mismo, se considera que asumen competencias en esta materia la entidad de regulación, es decir, la CMT, y la Agencia Estatal de Radiocomunicaciones, creada con la nueva Ley. ${ }^{27}$

Este último aspecto se debe tomar en cuenta, porque el ejercicio de competencias administrativas en torno al espectro radioeléctrico en los distintos organismos que forman parte de la Administración de telecomunicaciones permite luego elaborar políticas más acordes con las necesidades del sector, ya que - siguiendo la filosofía de la Decisión Espectro Radioeléctrico- es necesario tener clara la importancia que tiene trascender los aspectos técnicos del espectro radioeléctrico y vincularlos con aquellos de carácter económico, cultural, sanitario, de seguridad y sociales. De esa forma, se garantizaría su equitativa asignación, su racional utilización y su uso eficiente, de manera que pueda cumplirse con los fines de interés general que derivan de su carácter demanial.

\section{La habilitación administrativa para el uso del espectro radioeléctrico}

El carácter de recurso escaso del espectro puede considerarse como uno de los condicionantes de que su régimen de aprovechamiento esté estructurado de tal forma que se relacione con el otorgamiento de un título habilitante para la prestación de un servicio público.

Por lo general, la técnica de intervención o título habilitante que se ha utilizado es la concesión, por ser este un recurso escaso; sin embargo, esta es una cuestión del todo aleatoria, ya que la técnica de intervención puede ser otra.

27 Al respecto, véanse los artículos 46-48 de la ley 32/2003. 
$\mathrm{Al}$ respecto, en la línea de cuestionamiento general a la figura de la concesión administrativa, consideramos que, en la medida que el procedimiento para otorgar el espectro radioeléctrico sea el de un concurso público, es decir, uno en el que se garantice la transparencia y la igualdad del aprovechamiento del recurso, entonces podrá prescindirse de la concesión.

En el caso del Perú, el derecho de uso del espectro radioeléctrico está directamente vinculado con el otorgamiento de una concesión o de una autorización administrativa ${ }^{28}$ dependiendo del tipo de servicio de telecomunicaciones que se preste. La asignación ${ }^{29}$ de una determinada porción del espectro se realizará mediante resolución de la administración sectorial, sobre la base de lo que se establezca en el Plan Nacional de Asignación de Frecuencias (PNAF). ${ }^{30} \mathrm{Al}$ respecto, la cláusula 15 del contrato de concesión para la prestación de servicio portador y servicio telefónico local en las ciudades de Lima y Callao suscrito entre el Estado peruano y la CPTSA establece: ${ }^{31}$

\section{CLAUSULA 15. USO DEL ESPECTRO RADIO ELECTRICO}

La concesión también comprende la autorización de uso de las frecuencias y bandas de frecuencias que tiene asignada la EMPRESA CONCESIONARIA a la FECHA EFECTIVA para la prestación de los SERVICIOS PORTADORES y FINALES, comprendidos en este CONTRATO, y tendrá derecho también a obtener en el futuro, previa solicitud al MINISTERIO, las autorizaciones respectivas para el uso de frecuencias y bandas de frecuencias que adicionalmente requiera

28 Al respecto, véase el artículo 210 del Texto Único Ordenado del Reglamento General de la Ley de Telecomunicaciones.

29 Al respecto, véase el artículo 209 del Texto Único Ordenado del Reglamento General de la Ley de Telecomunicaciones.

30 Aprobado por resolución ministerial 187-2005-MTC-03, de 1 de abril de 2005. De acuerdo con lo dispuesto en la Sección II de la citada resolución, es necesario distinguir los siguientes conceptos:

«2.1 Atribución (de una banda de frecuencias): inscripción en el Cuadro de atribución de bandas de frecuencia, de una banda de frecuencias determinada, para que sea utilizada por uno o varios servicios de Radiocomunicación terrenal o espacial o por el servicio de radioastronomía en condiciones especificadas. Este término se aplica también a la banda de frecuencias considerada.

2.2 Adjudicación (de una frecuencia o de un canal radioeléctrico): inscripción de un canal determinado en un plan, adoptado por una conferencia competente, para ser utilizado por una o varias administraciones para un servicio terrenal o espacial en uno o varios países o zonas geográficas determinadas y según condiciones especificadas.

2.3 Asignación (de una frecuencia o de un canal radioeléctrico): autorización que se da para que una estación radioeléctrica utilice una frecuencia o un canal radioeléctrico determinado en condiciones especificadas».

31 Contratos de Concesión con CPT S. A. ENTEL PERU S. A. (Hoy Telefónica del Perú S. A. A.). Lima: Ed. Organismo Supervisor de Inversión Privada en Telecomunicaciones-OSIPTEL, 2001 , p. 236. 
para la prestación de los servicios públicos materia de concesión. La EMPRESA CONCESIONARIA tendrá derecho a participar en los procedimientos futuros aplicables relativos a la asignación de frecuencias a fin de alcanzar los REQUISITOS DE EXPANSION DE RED establecidos en la Sección 8.05.

En España, aunque el antiguo régimen de títulos habilitantes para el acceso a la prestación de servicios de telecomunicaciones fue sustituido por uno que sigue la filosofía de intervención mínima del ámbito comunitario y al que se denomina autorización general — que, en realidad, es una técnica de control preventivo- , dicho cambio no se ha producido con los títulos habilitantes para la asignación del espectro radioeléctrico. Al mantenerse el carácter demanial del espectro, la afectación se realizará mediante la concesión ${ }^{32}$ o la autorización administrativa, ${ }^{33}$ mientras que el uso común será libre.

Entonces, la diferencia básica que encontramos entre el sistema peruano y el español es que, en el primer caso, la habilitación para el aprovechamiento del espectro radioeléctrico se incorpora en el título habilitante (concesión o autorización administrativa) que da acceso a la prestación del servicio de telecomunicaciones y, además, su asignación concreta se realiza por medio de un acto administrativo posterior. En cambio, en el caso español, se ha distinguido entre el mecanismo de acceso a la prestación de servicios y la habilitación para el uso del espectro radioeléctrico, sin acaso estar desvinculados, ya que, en la medida de que la verificación de la comunicación previa sea conforme a derecho y se acredite la condición de operador, podrá solicitarse la asignación de frecuencia, que, en este caso específico, será una concesión administrativa.

En los casos de personas que no tengan la calidad de operadores, de manera que se trate de una reserva del derecho de uso espacial no privativo del dominio público, o si se otorga el derecho de uso privativo para autoprestación del solicitante, entonces se requerirá de autorización administrativa.

Finalmente, otro aspecto importante en el que podemos encontrar diferencias entre el ordenamiento español y el peruano es que el primero ha delimitado la habilitación teniendo en cuenta los distintos tipos de uso que puede hacerse del dominio público radio eléctrico: ${ }^{34}$

- El uso común general es una modalidad de utilización de baja intensidad en la que no se ha hecho ninguna reserva, de ahí su carácter libre y

\footnotetext{
Al respecto, véase el inciso d) del artículo 44.1 de la ley 32/2003.

Al respecto, véase el artículo 45.1 de la ley 32/2003.

34 En este punto, seguimos los planteamientos de MOLINA, A. Op. cit., p. 60 y de LAGUNA DE PAZ, J. C. Op. cit., pp. 117-120.
} 
gratuito. ${ }^{35}$ "Como contrapartida, los servicios no deberán producir interferencias ni solicitar protección frente a otros servicios de telecomunicaciones autorizados de categoría diferente». ${ }^{36}$

- El uso común especial es aquel que conlleva una especial intensidad, aunque no priva a los terceros de su uso libre pero requiere de un título habilitante. ${ }^{37}$ En el caso español, si bien no se define en qué consiste este uso, la ley 32/2003 establece en qué actividades se requiere autorización demanial..$^{38}$

- El uso privativo es aquel que impide o condiciona su uso por terceros. Supone una reserva exclusiva de la utilización de una porción de frecuencias. Su asignación requerirá de concesión administrativa. ${ }^{39}$

- La afectación demanial permite a las Administraciones públicas y a los entes públicos dependientes de ellas usar el dominio público para la prestación de servicios o la explotación de redes de telecomunicaciones en régimen de autoprestación y sin contraprestación económica de terceros. ${ }^{40} \mathrm{La}$ afectación es definida como un acto administrativo en virtud del cual se adscribe un bien demanial a un uso o servicio público. ${ }^{41}$ Esta afectación está excluida para actividades de naturaleza comercial, por lo que, básicamente, se trata de la utilización del espectro para la ejecución directa de servicios públicos. ${ }^{42}$

En el caso peruano, esta diferenciación de usos del demanio no ha sido asumida por el legislador peruano en la LTel ni en el decreto supremo 0272004-MTC, de 9 de julio de 2004, Texto Único Ordenado del Reglamento General de la Ley de Telecomunicaciones (en adelante RTel). Es necesario remitirse al Plan Nacional de Atribución de Frecuencias (PNAF), el mismo que, sin seguir las categorías expuestas, sino estableciendo como pauta una

35 Al respecto, véase el artículo 45.1 in fine del artículo 45.1 de la ley 32/2003.

36 MedinA, E. "Régimen jurídico aplicable al uso del espectro radioeléctrico. La tasa por reserva del dominio público radioeléctrico. La protección frente a las emisiones radioeléctricas». En J. M. VILLAR URÍBARRI (dir.). La nueva regulación de las telecomunicaciones, la televisión e Internet. Navarra: Aranzadi, 2003, p. 221.

37 Ib. considera únicamente el uso especial y lo define de la siguiente manera: "Se considera uso especial el de bandas, sub bandas, canales y frecuencias que se señalen, en el Cuadro Nacional de Atribución, como de uso compartido, sin exclusión de terceros, no considerado como de uso común, por radioaficionados o para otros fines de mero entretenimiento u ocio sin contenido económico».

38 Al respecto, véanse los incisos a) y b) del artículo 45.2 de la ley 32/2003.

39 Al respecto, véase el segundo párrafo del inciso b) del artículo 45.2 de la ley 32/2003.

40 Al respecto, véase el inciso d) del artículo 44.1 de la ley 32/2003.

41 Molina, A. Op. cit., p. 60.

42 Ib., p. 61. 
jerarquía de derechos, distingue, para el caso de la habilitación del uso del espectro, entre servicios "primarios», servicios "permitidos» y servicios "secundarios", los cuales explicaremos a continuación.

Por otro lado, el marco jurídico peruano únicamente ha regulado el aspecto referido a la atribución de bandas de frecuencias para la operación de los servicios de telecomunicaciones de las Fuerzas Armadas y Policía Nacional. ${ }^{43}$ Sin embargo, en lo referido a la utilización del dominio público radioeléctrico por la Administración sectorial o general, no hay una regulación concreta en la LTel ni en el RTel, lo que sí pueden encontrarse son reservas de frecuencias en el PNAF para la utilización por parte de entes estatales en servicios de radiodifusión sonora y de televisión.

\section{Regulación del espectro: el Plan Nacional de Asignación de Fre- cuencias (PNAF)}

El PNAF es un documento técnico normativo ${ }^{44}$ — que está sujeto a cambios para garantizar su permanente actualización-, ${ }^{45}$ cuya importancia radica en que en él se consigna el cuadro de atribución de frecuencias de los servicios de telecomunicaciones, así como las normas generales para la utilización del espectro radioeléctrico. ${ }^{46}$

En el PNAF se establece el tipo de uso de la banda o el uso común del espectro radioeléctrico, así como la clase y categoría de servicios para cada banda. ${ }^{47}$ Cuando en una casilla del Cuadro de Atribución de Bandas de Frecuencias, una banda de frecuencias se atribuye a varios servicios, ya sea en todo el mundo, en una región ${ }^{48}$ puede distinguirse, dentro de una jerarquía de derechos, los servicios "primarios», "permitidos» y «secundarios». ${ }^{49}$

43 Al respecto, véase el tercer párrafo del artículo 207 del RTel.

44 Al respecto, véase el segundo párrafo del artículo 207 del RTel.

45 Al respecto, véase el quinto párrafo del artículo 207 del RTel.

46 Al respecto, el artículo 4 de la resolución ministerial 187-2005-MTC-17 dispone lo siguiente: "Los servicios que operen con autorización de la Administración Peruana de Telecomunicaciones deberá cumplir con lo especificado en el cuadro de atribución de bandas de frecuencias y sus notas adicionales».

47 Al respecto, véase el cuarto párrafo del artículo 207 del RTel.

48 Como se sabe, desde el punto de vista de la atribución de las bandas de frecuencias, se ha dividido el mundo en tres regiones, de manera que el Perú pertenece a la región 2. La región 1 corresponde a Europa, África, Siberia y algunos países de Oriente medio; la región 2 es el continente americano; y la región 3 corresponde a Australia, sur-sureste asiático y gran parte del Pacífico sur. Las zonas de adjudicación especiales son la zona africana de radiodifusión, la europea, la marítima europea y la zona tropical.

49 Al respecto, véase la Sección II del artículo 4 de la resolución ministerial 187-2005MTC- 17 . 
Los servicios de tipo "primario" gozan de los mismos derechos de uso que los «permitidos»; sin embargo, en la preparación de planes de frecuencia, los servicios "primarios", en relación con los servicios "permitidos", serán los primeros en escoger frecuencias.

En cambio, los servicios «secundarios» tienen la obligación de no causar interferencias por medio de sus estaciones a las frecuencias asignadas, o por asignarse, a los servicios primarios o servicios permitidos. Tampoco podrán reclamar interferencias en sus frecuencias causadas por estaciones de estos dos servicios. Por el contrario, sí les asiste el derecho de protección frente a interferencias de estaciones del mismo servicio o de servicios secundarios a los que se les asigne frecuencias ulteriormente.

El Cuadro de Atribución de Bandas de Frecuencias - que forma parte del PNAF- distingue la atribución de bandas para región 2 - a la que pertenece el Perú- de la atribución al Perú de esas bandas a los diversos servicios de radiocomunicaciones, que, a su vez, comprende la atribución de las bandas a los servicios y las notas y observaciones relativas al tipo de explotación indicado.

Teniendo como base el PNAF, es necesario tener claro que, cuando se convoca a un concurso público de ofertas para el otorgamiento de una concesión o de una autorización administrativa para poder prestar un determinado servicio de telecomunicaciones o de radio difusión, previamente ya están establecidas las frecuencias a cuyo uso será afectado de acuerdo con lo que se establezca en el PNAF. ${ }^{50}$ No obstante, también es posible que se dé el supuesto en el que, mediante la presentación de una solicitud, tanto para el otorgamiento de una concesión como de una autorización administrativa, en cuyo caso hay que atender a las notas y observaciones que se realicen con respecto al servicio solicitado, ya que las mismas pueden establecer

so Por ejemplo, de acuerdo con el Cuadro de Atribución de Bandas de Frecuencias, a los servicios FIJO, FIJO POR SATELITE, MOVIL (salvo móvil aeronáutico) y de radioastronomía, dentro de la banda de $\mathrm{GHz} 39,5-54,25$, se les ha atribuido una frecuencia de $\mathrm{GHz}$ $42,5-43,5$, y en las NOTAS y OBSERVACIONES se ha establecido la P68, que dispone que "las bandas comprendidas entre $2200-2400 \mathrm{MHz} ; 25,25-27,5 \mathrm{GHz} ; 27,5-28,35$ $\mathrm{GHz} ; 29,10-29,25 \mathrm{GHz} ; 31,00-31,30 \mathrm{GHz} ; 37,35-37,55 \mathrm{GHz}, 38,05-38,25 \mathrm{GHz}$, 38,6 - $40 \mathrm{GHz} ; 40,5-42,5 \mathrm{GHz}$ y 42,5 - 43,5 GHz están atribuidas a título primario para la prestación de servicios públicos de telecomunicaciones utilizando sistemas de acceso fijo inalámbrico. El otorgamiento de la concesión y la asignación de espectro para la explotación de dichos servicios será mediante concurso público de ofertas para la Provincia de Lima y la Provincia Constitucional del Callao. Este mecanismo de concurso público de ofertas no se aplicará a los concesionarios que migren a la banda comprendida entre 2200 - $2400 \mathrm{MHz}$; de acuerdo a lo dispuesto en el artículo 224 del Texto Único Ordenado del Reglamento General de la Ley de Telecomunicaciones». 
especificaciones técnicas o restricciones a la disponibilidad en las frecuencias que hayan sido atribuidas. ${ }^{51}$

Otro aspecto que debe señalarse con relación al PNAF es que, vía la resolución ministerial 098-2000-MTC/15.03, de 24 de febrero de 2000, dicho documento fue adecuado a los Lineamientos de Política de apertura del Mercado de Telecomunicaciones del Perú con el objetivo de garantizar la más eficiente administración del recurso, lo que permite al concesionario operador de servicios públicos de telecomunicaciones que tiene asignada una banda de frecuencias para uno o más de dichos servicios prestar adicionalmente otros servicios en la banda asignada, aunque no se encuentre atribuida para los servicios adicionales. ${ }^{52}$

Si bien es una norma que apunta hacia un uso eficiente del espectro por parte del operador, dicho dispositivo establece como requisito que previamente se haya otorgado la concesión para cada servicio que quiera prestar dentro de determinada banda, así como que se cumpla con las obligaciones, las características técnicas de operación y la normativa vigente. ${ }^{53}$

Una de las reglas importantes que debe seguirse una vez sea asignada la frecuencia al operador de servicios de telecomunicaciones es la referida a que no son modificables las características de instalación y operación autorizadas para el uso o explotación de frecuencias, la potencia de transmisión y otros parámetros relativos al uso del espectro radioeléctrico. Ello, salvo que antes se haya obtenido la correspondiente autorización del MTC o este, de oficio, haya dispuesto el cambio de las características técnicas asignadas, cuando se ponga en peligro la vida o la salud de las personas, a efectos de dar cumplimiento a lo dispuesto en la norma que establece los límites máximos permisibles de radiaciones no ionizantes en telecomunicaciones y las normas técnicas del servicio de radiodifusión, en cumplimiento

51 Por ejemplo, de acuerdo con el Cuadro de Atribución de Bandas de Frecuencias, a los servicios de RADIODIFUSIÓN, dentro de la banda $\mathrm{KHz} 14.250$ - 18.068, se les ha atribuido la frecuencia $\mathrm{KHz} 15.600$ - 15800, y en las NOTAS y OBSERVACIONES se ha establecido la P24, que dispone que "las bandas de $5900-5950 \mathrm{KHz}, 7300-7350 \mathrm{KHz}$, $9400-9500 \mathrm{KHz}, 11600-11650 \mathrm{KHz}, 12050-12100 \mathrm{KHz}, 13570-13600 \mathrm{KHz}, 13800$ - $13870 \mathrm{KHz}, 15600-15800 \mathrm{KHz}, 17480-17550 \mathrm{KHz}, 18900$ - $19020 \mathrm{KHz}$, a partir del 1 de abril del año 2007 será atribuida al servicio de radiodifusión, y están sujetas a la aplicación del procedimiento del artículo 12 del Reglamento de Radiocomunicaciones de la UIT. La UIT recomienda que se utilicen estas bandas a fin de facilitar la introducción de las emisiones moduladas digitalmente según dispone la Resolución 517(Rev. CMR- 03)».

52 Al respecto, véase el artículo 1 de la resolución ministerial 098-2000-MTC/15.03. Aunque esta es una disposición que ya se había insertado anteriormente en el artículo 214 del RTel, la adecuación del PNAF era necesaria.

53 Al respecto, véase el artículo 2 de la resolución ministerial 098-2000-MTC/15.03. 
de las normas que el MTC emita sobre el sistema de gestión y control de espectro. ${ }^{54}$

\section{El uso eficiente del espectro radioeléctrico y su control}

El espectro radioeléctrico es un recurso natural ampliamente demandado por los operadores que utilizan redes radioeléctricas para ofrecer sus servicios, lo que ha motivado el interés dentro de la política del sector por su aprovechamiento racional y porque se regule su uso eficientemente. ${ }^{55}$

Tal es el objetivo de eficacia en la gestión del espectro radioeléctrico que deberá presidir toda actuación de la Administración sectorial relacionada con el dominio público radioeléctrico; la consecución de dicha finalidad evitará que, en un futuro, se produzcan situaciones de ineficiencia, del todo indeseables en toda buena gestión del espectro. ${ }^{56}$

Precisamente, en el ámbito europeo, la Decisión Espectro Radioeléctrico se aprobó dentro de la filosofía de que los países miembros deben coordinar sus políticas, y cuando sea necesario unas condiciones armonizadas, con respecto a la disponibilidad y al uso eficiente del espectro radioeléctrico. ${ }^{57}$

Además, introduce una importante consideración, según la cual «la política del espectro no puede basarse exclusivamente en parámetros técnicos, sino que debe también tener en cuenta consideraciones económicas, políticas, culturales, sanitarias y sociales». ${ }^{58}$

Dentro de esta línea, la Decisión incide en el hecho de que la demanda cada vez mayor de una oferta limitada de espectro radioeléctrico disponible puede generar presiones contrapuestas para dar cabida a los distintos grupos de usuarios del espectro radioeléctrico en sectores como las telecomunicaciones, la radiodifusión, el transporte, las fuerzas de seguridad y militares

54 Al respecto, véanse los artículos 220-221 del RTel.

55 Como sostiene LAGUNA DE PAZ, J. C. Op. cit., p. 111, es necesario tener en cuenta que "los Estados disponen de un apreciable margen de actuación en la definición de la política del espectro radioeléctrico", que "se acepta que la distribución de las frecuencias debe responder a las necesidades y prioridades de cada país, por lo que sólo una reducida parte de los usos del espectro se encuentra armonizada a nivel internacional» y que "las frecuencias disponibles para algunos servicios pueden variar así de un país a otro, lo que dificulta la introducción de servicios paneuropeos y globales».

56 Calvo, A. y J. SANMARtin. "Artículo 44.- Facultades de Gobierno para la gestión del dominio público radioeléctrico». En J. Cremades y J. Rodriguez-Arana (dirs.). Op. cit., p. 593.

57 Al respecto, véase el considerando 1 y el artículo 1.1 de la Decisión Espectro Radioeléctrico.

58 Al respecto, véase el primer párrafo del considerando 8 de la Decisión Espectro Radioeléctrico. 
y la comunidad científica. De todo ello se deriva la importancia de que la política del espectro radioeléctrico deba de tener en cuenta a todos los sectores y equilibrar sus necesidades respectivas. ${ }^{59}$

A la demanda creciente del espectro debe añadirse, como elemento que sustenta la búsqueda de eficiencia en los servicios de telecomunicaciones, el que no todas las partes del mismo reúnen las mismas propiedades físicas. ${ }^{60}$ Cada frecuencia presenta unas características típicas, de lo que se deduce que determinadas bandas estén especialmente indicadas para proporcionar unos servicios concretos, lo que provoca, en ocasiones, conflictos entre distintos servicios que pugnan por la misma banda.

En el esquema peruano, se han identificado dos aspectos vinculados directamente con el uso eficiente del espectro radioeléctrico: en primer lugar, la promoción de inversiones, lo que contribuiría a aumentar la cobertura y calidad de los servicios de telecomunicaciones; y, en segundo lugar, el desarrollo del mercado y de la competencia en el ámbito de los servicios de telecomunicaciones. ${ }^{61}$

Todas estas motivaciones se han visto reflejadas en el marco jurídico que regula los servicios de telecomunicaciones en el Perú. Así, respecto al uso eficiente del espectro, el RTel dispone:

Artículo 21.- La asignación de espectro para servicios públicos, estará sujeta al cumplimiento de metas de uso de espectro, las cuales estarán contempladas en el instrumento que lo asigna. Entiéndase por metas de uso de espectro la obligación y compromiso que tiene la empresa concesionaria de utilizar en forma eficiente y efectiva el espectro asignado, de tal manera que se garantice el uso eficiente de dicho recurso.

Sobre esta base, vía la resolución ministerial 087-2002-MTC/15.03, publicada el 11 de febrero de 2002, se aprobó la norma de metas de uso del espectro radioeléctrico de servicios públicos de telecomunicaciones. En ella, se establecen los principios que lo informan y que se constituyen en los lineamientos sobre la base de los cuales la autoridad competente funda-

${ }^{59}$ Al respecto, véase el segundo y tercer párrafos del considerando 8 de la Decisión Espectro Radioeléctrico.

60 GRETEL. Competencia y regulación en los mercados de telecomunicaciones, el audiovisual e Internet. Madrid: Colegio Oficial de Ingenieros de Telecomunicación, 1998, p. 220.

61 Al respecto, véase los incisos b) y c) del artículo 1 de la resolución ministerial 087-2002MTC/15.03. 
mentará su evaluación y decisión en los casos de uso ineficiente ${ }^{62}$ del espectro radioeléctrico.

El punto de partida de esta norma es que, sobre la base de que el espectro radioeléctrico es un recurso escaso de oferta fija, este debe estar asignado a aquellos concesionarios que mejor contribuyan con el desarrollo de los servicios de telecomunicaciones — sin acaso distinguirlos - de manera eficiente. ${ }^{63}$

En la evaluación que realice la autoridad sectorial sobre el uso eficiente del espectro radioeléctrico, esta tendrá que observar los principios de igualdad de trato, imparcialidad y transparencia, de tal forma que se garantice al operador que no será discriminado frente a otros operadores, que la evaluación va a ser objetiva, y que la decisión que se tome estará dentro del marco de actuación de la Administración y que tal decisión tendrá la motivación correspondiente. ${ }^{64}$

De acuerdo con la norma de Metas de Uso de espectro radioeléctrico, la autoridad competente para realizar la evaluación será la Unidad Técnica Especializada en Telecomunicaciones (UECT), perteneciente al MTC. Las referidas Metas de Uso serán establecidas por la propia UECT ${ }^{65}$ y constarán como anexos técnicos al instrumento que habilite al operador a prestar el respectivo servicio de telecomunicaciones.

La norma ha previsto que la verificación del cumplimiento de las Metas de Uso del espectro radioeléctrico deba realizarse desde que se inicia la prestación del servicio de telecomunicaciones por parte de los operadores. Sin embargo, luego de la finalización de los plazos establecidos en los anexos que contienen las Metas de Uso de Espectro Radio Eléctrico, las verificaciones serán de carácter periódico. ${ }^{66}$

62 De acuerdo con el artículo 3 de la resolución ministerial 087-2002-MTC/15.03, "se entiende por uso ineficiente del espectro al no uso o uso parcial injustificado de las frecuencias asignadas para la prestación de servicios públicos de telecomunicaciones, medido de acuerdo a las Metas de Uso aprobadas mediante el acto administrativo correspondiente. Dichas Metas de Uso constituyen valores mínimos que deben cumplir los concesionarios de acuerdo al período de tiempo establecido en los correspondientes anexos técnicos sobre Metas de Uso de Espectro Radioeléctrico».

63 Al respecto, véase el inciso a) del artículo 1 de la resolución ministerial 087-2002-MTC/ 15.03.

64 Al respecto, véanse los incisos d) y e) del artículo 1 de la resolución ministerial 087 2002-MTC/15.03.

65 De acuerdo con lo dispuesto en los numerales 2 y 3 del artículo 4 de la resolución ministerial 087-2002-MTC/15.03, deberá observarse el Plan Mínimo de Expansión del servicio o, en caso de que este haya finalizado, deberá basarse en los indicadores de las Metas de Uso del último año.

66 Al respecto, véase el último párrafo del artículo 4 de la resolución ministerial 087-2002MTC/15.03. 
El procedimiento ${ }^{67}$ de verificación será realizado por la UECT, de acuerdo con las pautas establecidas en las normas de Metas de Uso, y podrá generar, en caso de uso indebido del espectro, la revocación parcial (cuando el concesionario haya cumplido solo parcialmente y de manera injustificada con las Metas de Uso en los plazos establecidos), por lo que los canales asignados no utilizados revertirán al Estado; o la revocación total (cuando el concesionario no ha utilizado el espectro radioeléctrico), que podrá producir, además, la cancelación de la concesión. ${ }^{68}$

La actividad de verificación debe estar considerada dentro de lo que es el control de espectro radioeléctrico —que consiste en comprobar que el uso real que se hace del espectro se ajusta a los objetivos y regulación establecidos- ${ }^{69}$ ya que, dentro de la obligación general del Ministerio del sector de velar por el correcto funcionamiento de los servicios de telecomunicaciones que utilicen el espectro, se encuentra la de asignar el uso racional del mismo. $^{70}$

Las acciones de control ${ }^{71}$ tienen como objetivo el realizar comprobaciones técnicas de las emisiones radioeléctricas e identificar y localizar interferencias perjudiciales y demás perturbaciones a los sistemas y servicios de telecomunicaciones. ${ }^{72}$ Asimismo, estarán dirigidas a detectar a las personas que presten servicios de telecomunicaciones en condiciones técnicas distintas de las establecidas ${ }^{73}$ por la Administración sectorial o sin la correspondiente concesión, autorización, permiso o licencia.

67 Al respecto, véase el artículo 7 de la resolución ministerial 087-2002-MTC/15.03.

68 Al respecto, véase el artículo 8 de la resolución ministerial 087-2002-MTC/15.03 y el artículo 225.1 del RTel.

69 MARZO, J. Op. cit., p. 160.

70 Al respecto, véase el artículo 229 del RTel.

71 Idem.

72 Al respecto, los operadores deberán observar lo dispuesto en el artículo 219 del RTel:

"Artículo 219.- Toda estación radioeléctrica operará sin afectar la calidad ni interferir otros servicios de radiocomunicaciones autorizados. En caso de interferencia perjudicial, el causante está obligado a suspender de inmediato sus operaciones hasta corregir la interferencia a satisfacción del Ministerio».

73 Al respecto, el artículo 223 del RTel establece la prohibición general del uso de estaciones radioeléctricas para finalidad diferente de la autorizada. Sin embargo, también establece la posibilidad de que se exceptúe dicha regla cuando se utilicen las estaciones radioeléctricas en apoyo de los sistemas de defensa. 


\section{Numeración}

\section{Necesidad de un ordenamiento de la numeración}

$\mathrm{Al}$ igual que el espectro radioeléctrico, la numeración constituye un recurso escaso necesario para la operatividad de los servicios de telecomunicaciones. Por ello, es importante su regulación y la adecuada planificación por parte de la Administración sectorial. Dos son las motivaciones que pueden identificarse para el establecimiento de un ordenamiento de la numeración: ${ }^{74}$

- La numeración es un recurso escaso que requiere una gestión eficiente a través de la Administración sectorial y de forma independiente de los operadores de los servicios de telecomunicaciones. ${ }^{75}$ Asimismo, es un recurso limitado por razones técnicas (capacidad limitada en el tratamiento de las redes, dimensionamiento del plan de numeración y el número máximo de cifras utilizable recomendado por la Unión Internacional de Telecomunicaciones - UIT) y por la propia universalización del servicio telefónico fijo, así como por la presencia de nuevos operadores que prestan nuevos servicios de telecomunicaciones y que precisan, para esos servicios, de nuevos números. ${ }^{76}$

- Las implicancias de la numeración sobre las decisiones de consumo de los usuarios pueden convertirse en un obstáculo para los operadores entrantes en el mercado. Al respecto, como sostiene Sánchez Rodríguez, cuando aparecen en el mercado multitud de operadores debido al proceso de liberalización, la numeración es, además, un medio técnico y jurídico por el que se debe fomentar la competencia entre operadores, ya que, al tratarse de un recurso escaso, es posible que los operadores dominantes pretendan acapararla y controlarla, de modo que no puedan entrar nuevos operadores. ${ }^{77}$

Estas motivaciones conducen no solo a que se regule un marco normativo general sobre la gestión con control de la utilización del recurso de

74 En este punto, seguimos el planteamiento de GRETEL. Competencia y regulación en los mercados de telecomunicaciones, el audiovisual e Internet. Op. cit., p. 237.

75 En este mismo sentido, MONTERO, J. J. y H. BROKELMANN. Telecomunicaciones y televisión. La nueva regulación en España. Valencia: Tirant lo Blanch, 1999, p. 273 consideran que la exigencia de una gestión eficiente evitará el colapso de las estructuras y permitirá la introducción de nuevos servicios.

76 Seguimos el planteamiento de SÁNCHez RODRícuez, A. J. Derecho de las telecomunicaciones. Nuevo Derecho y nuevo mercado. Madrid: Dykinson, 2002, p. 115.

77 SÁNCHEZ RODRÍGUEZ, A. J. Op. cit., p. 116. 
numeración, sino también que se instaure un plan de numeración que sea el referente de todos los operadores y a que se implanten procedimientos que eliminen cualquier barrera que afecte la competencia entre operadores, como son los mecanismos de selección y la portabilidad. ${ }^{78}$

El número del abonado a un servicio público de telecomunicaciones (servicio de telefonía fija, los servicios públicos móviles tales como el servicio telefónico móvil, el servicio de comunicaciones personales, el servicio móvil de canales múltiples de selección automática-troncalizado, el servicio móvil por satélite, así como otros servicios públicos definidos por la Administración sectorial) tradicionalmente cumplió tres funciones: ser el medio de identificación del abonado, constituirse en un medio de identificación de los operadores de servicios y ser utilizado con propósitos técnicos para identificar los canales por medio de los cuales se transmiten las comunicaciones. ${ }^{79}$ Asimismo, de forma específica pueden mencionarse las siguientes funciones:

- El número por sí mismo es un indicativo directo del tipo de servicio, la tarifa y el destino geográfico.

- Cumplen una función comercial, ya que los números cuyos dígitos son fácilmente identificables pueden tener un alto valor en el mercado.

- Posibilitan el acceso a servicios públicos esenciales (policía, atención sanitaria de urgencia, etc.).

A pesar de la importancia de la numeración y de su funcionalidad en el ámbito de los servicios públicos de telecomunicaciones, en el Perú, la LTel y el RTel no han regulado dicha temática como se ha hecho en el caso del espectro radioeléctrico. Si bien las directrices básicas de la utilización de la numeración tienen su referente en los Planes Nacionales de Telecomunicaciones (PNT) ${ }^{80}$ solo hasta la expedición de la resolución suprema

78 En términos similares, véase SÁNCHEZ RODRícuez, A. J. Op. cit., p. 118.

79 Nihoul. P., y P. RODFORD. EU Electronic Communications Law. Competition and regulation in the European Telecommunications Market. Oxford: Oxford University Press, 2004, p. 130.

80 Actualmente, a pesar de su importancia para el desarrollo tecnológico, económico y normativo del sector de las telecomunicaciones, el MTC no cuenta con un plan nacional de telecomunicaciones. El único plan aprobado a la fecha data del año 1978; sin embargo, con los avances tecnológicos y el crecimiento del sector, ya se encuentra desactualizado. El artículo 17 del ya derogado decreto supremo 06-94-TCC, antiguo Reglamento de la Ley de Telecomunicaciones, definía el Plan Nacional de Telecomunicaciones como «el documento que contiene los planes técnicos fundamentales que sobre la base del principio de integración de redes, sistemas y servicios, establece las pautas y lineamientos técnicos básicos que aseguran la integración e implementación de los servicios 
022-2002-MTC, de 31 de agosto de 2002, se contó con un Plan Técnico Fundamental de Numeración (PTFN), el cual fue aprobado con el objeto de establecer las bases para una adecuada administración y una eficiente asignación, supervisión y uso de la numeración, considerada como un recurso escaso, así como para definir las estructuras de numeración para la prestación de servicios públicos de telecomunicaciones. ${ }^{81}$

\section{Características básicas del Plan Técnico Fundamental de Nume- ración (PTFN)}

El PTFN aprobado en el Perú es un documento concordante con la Recomendación UIT E.164 («Plan Internacional de Numeración de Telecomunicaciones Públicas») y con los acuerdos internacionales de telecomunicaciones suscritos por el Perú. De igual forma, recoge la versión realizada con la participación de la UIT en el año $1999 .^{82}$

El punto de partida para analizar el PTFN es la consideración de la numeración como un recurso escaso; sin embargo, no queda claro si dicho numeración tiene carácter demanial, como sucede con el espectro radioeléctrico. La duda surge por las siguientes razones: por un lado, no hay una declaración expresa del legislador peruano respecto a que la numeración sea considerada como bien de dominio público y, por otro lado, si bien para que uno pueda solicitar la asignación del recurso de numeración es necesario tener la calidad de operador con concesión vigente, no hay ninguna disposición que establezca que el otorgamiento de la concesión comprenda, además, la asignación de numeración.

A nuestro parecer, además de las razones expuestas hay que considerar que los recursos de numeración no tienen la calidad de dominio público a pesar de su carácter escaso, ya que el mecanismo de asignación establecido

de telecomunicaciones a nivel nacional y establecía que su elaboración corría a cargo del MTC y que debía ser aprobado por resolución suprema refrendada por el Titular del Ministerio; asimismo, disponía que su actualización o revisión debía realizarse obligatoriamente en períodos no mayores de cinco (5) años y que el MTC podía convocar a audiencia pública previamente a la aprobación de las modificaciones del Plan, a fin de recoger los aportes de las personas o entidades especializadas. Los planes nacionales de desarrollo de las telecomunicaciones deberán elaborarse tomando en cuenta el citado Plan. Desde la fecha de expedición de la glosada norma, no se aprobó ningún Plan; el año 1998, se elaboró un documento técnico que se consideraba como un Plan Nacional de Telecomunicaciones. Con la expedición del nuevo texto del RTel (decreto supremo 027-2004-MTC), el texto de la norma del artículo 17 permanece vigente en términos similares a los señalados anteriormente en el artículo 20 del Rtel; sin embargo, como se refirió, el MTC no ha aprobado el referido Plan.

${ }_{81}$ Al respecto, véase el tercer considerando de la resolución suprema 022-2001-MTC.

82 La referencia es tomada de la Introducción al PTFN. 
por el legislador peruano es el de un acto administrativo y porque, a diferencia de la especificidad técnica de las bandas de frecuencias, los recursos de numeración pueden asignarse y generarse en caso de que una estructura de numeración no tenga series disponibles.

Ahora bien, es necesario poner énfasis en que la falta de reconocimiento en el Perú del carácter demanial del recurso de numeración no significa que la Administración sectorial no pueda establecer mecanismos de intervención en su ordenación (gestión y supervisión). Al contrario, es esta la vía para garantizar que la asignación de la numeración a los servicios públicos de telecomunicaciones es eficiente y se realiza respetando principios de igualdad, de oportunidades y de transparencia. ${ }^{83}$

En el Perú, lo que ha operado en el caso de la numeración es una reserva en lo que a gestión y administración del recurso se refiere, y no hay, en sentido estricto, titularidad respecto del mismo. Jurídicamente, la numeración es un res comunis omnium, que, no siendo demanio, tampoco es posible jurídicamente la apropiación a título exclusivamente privado. ${ }^{84} \mathrm{Se}$ gún Sánchez Rodríguez, "lo que se quiere con la reserva es la ineficacia de todo mecanismo de derecho privado en la utilización excluyente de este bien». ${ }^{85}$

El tratamiento de la numeración en España ${ }^{86}$ es similar al de la legislación peruana, ya que la ley 32/2003 no se pronuncia respecto de su naturaleza jurídica, sino que es considerada como recurso público, de manera que lo que se habría fijado es una reserva de un recurso esencial, en el

83 SÁNCHEZ RODRÍGUEZ, A. J. Op. cit., p. 118.

${ }^{84}$ Ib., pág. 119.

85 Ib. Al respecto, NIHOUL, P. y P. RODFORD. Op. cit., p. 131 consideran que, bajo el nuevo marco regulatorio comunitario de 2002, los números pueden ser transferidos comercialmente entre operadores; así, piensan que esta puede ser una forma de uso correcto de los mismos, ya que evita que estén en poder de operadores que, por dificultades económicas, no pueden hacer uso de ellos.

86 En el ámbito de la Unión Europea, el considerando 20 de la Directiva Marco hace referencia al tema de la numeración en los siguientes términos: "Para que las empresas puedan competir en el sector de las comunicaciones electrónicas, resulta esencial que el acceso a los recursos de numeración se base en criterios transparentes, objetivos y no discriminatorios». Asimismo, el artículo 10.2 de la Directiva Marco (cuya lectura debe hacerse conjuntamente con el artículo 5 de la Directiva autorización) dispone:

"Artículo 10. Numeración, denominación y direccionamiento [...]

2. Las autoridades nacionales de reglamentación velarán porque los planes y procedimientos de numeración se apliquen de forma que exista igualdad de trato entre todos los proveedores de servicios de comunicaciones electrónicas disponibles para el público. En particular, los Estados miembros garantizarán que las empresas a las que se haya atribuido una serie de números no discriminen a otros proveedores de servicios de comunicaciones electrónicas en lo que se refiere a las secuencias de números utilizadas para dar acceso a sus servicios». 
sentido del artículo 128.2 de la Constitución española. ${ }^{87}$ De esta forma, conforme lo dispone la ley española, la asignación de números solo supondrá el otorgamiento de derechos de uso. ${ }^{88}$

Por otro lado, también se considera que, en su calidad de recurso escaso, está sujeto a un régimen de planificación, por lo que se ha dispuesto que la aprobación de los planes de numeración estén a cargo del Gobierno, ${ }^{89}$ y que la gestión y control de los mismos queden a cargo de la entidad reguladora sectorial (la CMT). ${ }^{90}$

Un segundo punto importante es el referido a los objetivos de PTFN, los cuales son concordantes con las consideraciones expuestas en el apartado precedente; entre estos pueden distinguirse los siguientes: ${ }^{91}$

- el establecimiento de las bases para una adecuada administración y la oportuna supervisión y uso de la numeración mediante la asignación eficiente y no discriminatoria de los recursos disponibles;

- la definición de las estructuras de numeración para la prestación de los servicios públicos de telecomunicaciones con la finalidad de identificación de los destinos y/o equipos terminales de las diferentes redes públicas de telecomunicaciones;

- la facilitación del acceso a los diferentes servicios prestados por los operadores de las redes públicas de telecomunicaciones;

- el permiso de la interoperabilidad entre las redes y servicios de telecomunicaciones;

87 Respecto de la caracterización de los recursos de numeración realizada en España, LAGUNA DE PAZ, J. C. Op. cit., pp. 126-128 ha formulado tres importantes comentarios. En primer lugar, señala que la reserva al sector público del espacio público de numeración, con el fin de asegurar su disponibilidad para los servicios públicos de telecomunicaciones, podría conducir a una demanilización del bien. En segundo lugar, considera que, al estar la numeración al servicio de la expansión de las telecomunicaciones, el recurso de numeración debería adaptarse a las necesidades que requiera la proliferación de terminales de telecomunicación; de esta manera, es posible discutir el carácter de recurso limitado de numeración o del sistema que haya de aplicarse para la identificación; asimismo, recuerda que, aunque se tratase de recursos limitados, debe recordarse que la escasez no necesariamente supone la reserva del bien al sector público. Y, en tercer lugar, afirma que es necesario tener presente que el objeto de la reserva es el espacio público de numeración, de tal manera que la elaboración de guías electrónicas y los servicios especializados en suministro sobre números de abonado son actividades que se prestan en régimen de libre competencia.

${ }_{88}$ Al respecto, véase el primer párrafo del artículo 16.7 de la ley 32/2003.

89 Al respecto, véase el artículo 16.3 de la ley 32/2003.

90 Al respecto, véase el artículo 16.4 de la ley 32/2003.

91 Al respecto, véase el punto 1 del PTFN. 
- la facilitación del ingreso de nuevas empresas prestadoras de servicios de telecomunicaciones, de la incorporación de nuevos servicios y de la ampliación de los existentes;

- la facilitación al abonado, en la medida de lo posible, del reconocimiento de los diferentes servicios y sus proveedores; y

- el cumplimiento de los requerimientos estimados de numeración a largo plazo (no menos de veinte años).

Ahora bien, el PTFN define cuáles son los conceptos que sirven de base al plan, ${ }^{92}$ así como los distintos servicios especiales ${ }^{93}$ y los servicios suplementarios que, por medio de la numeración, pueden ser prestados a los abonados.

De otro lado, es necesario prestar atención respecto de la configuración que hace el PTFN de las estructuras de numeración, las que comprenden:

- la estructura del número internacional y la estructura del número nacional;

- la estructura de los números geográficos (estructura del número nacional [significativo] geográfico, estructura del número de abonado);

- la estructura de números no geográficos (estructura del número nacional (significativo) móvil, estructura de numeración para facilidades de red inteligente) $;^{94}$

- la estructura de numeración de servicios especiales (estructura de numeración de servicios especiales básicos, ${ }^{95}$ estructura de numeración de servicios especiales facultativos, estructura de numeración para servicios especiales con interoperabilidad);

92 Nos referimos, a las definiciones de prefijo (internacional y larga distancia nacional), indicativo de país (CC: Country Code), indicativo nacional de destino (NDC: Nacional Destination Code: Trunk Code, Destination Network), número de abonado (SN: Suscriber Number), número internacional, número nacional (significativo), números geográficos, números no geográficos, código de identificación del concesionario del servicio portador de larga distancia, códigos de acceso para comunicaciones de larga distancia mediante el uso de tarjetas de pago, códigos de acceso a servicios diversos.

93 Nos referimos a los servicios especiales, servicios especiales facultativos y servicios especiales con interoperabilidad.

94 Las facilidades de red inteligente comprendidas son serie 800 (servicio de cobro revertido automático o "llamada libre de pago»), serie 801 (servicio de pago compartido), serie 802 (número universal), serie 804 (número personal), serie 805 (llamadas masivas) telefoto), serie 806 (red privada virtual), serie 806 (audio servicios de valor adicional).

95 Los servicios especiales básicos comprendidos son 101 (centro de mantenimiento), 102 (servicio de reclamo por avería), 103 (informaciones de guía local y nacional), 104 (telegestión comercial), 105 (emergencia-policía), 108 (operadora internacional), 109 (operadora nacional), 111 (emergencia nacional), 115 (defensa civil), 116 (emergenciabomberos), 117 (emergencia hospital). 
- la estructura de numeración para los servicios suplementarios;

- la estructura de numeración para la identificación del concesionario del servicio portador de larga distancia;

- la estructura de numeración para las comunicaciones de larga distancia mediante el uso de tarjeta de pago;

- la estructura de numeración para el acceso a servicios diversos;

- la estructura de numeración de reserva;

- los prefijos $;^{96} \mathrm{y}$

- los indicativos (de país y larga distancia nacional).

Junto con las estructuras de numeración, se han delimitado las zonas o áreas de numeración geográfica, en las que los departamentos constituyen la unidad básica para la configuración de las zonas de numeración, de tal forma que uno o más departamentos conforman una zona de numeración cuya identificación será realizada mediante los códigos de áreas de numeración.

El PTFN ha establecido ocho zonas de numeración y considerado seis de ellas, habiendo reservado las zonas dos y tres, de acuerdo con el siguiente esquema:

\begin{tabular}{|c|l|}
\hline $\begin{array}{c}\text { Zona de } \\
\text { numeración }\end{array}$ & \multicolumn{1}{|c|}{ Cobertura geográfica (por departamentos) } \\
\hline 1 & Lima y Provincia Constitucional del Callao \\
4 & La Libertad, Ancash, San Martín y Amazonas \\
5 & Arequipa, Moquegua, Tacna, Puno e Ica \\
6 & Junín, Pasco, Huánuco, Ucayali, Huancavelica, Ayacucho y Loreto \\
7 & Tumbes, Piura, Lambayeque y Cajamarca \\
8 & Cusco, Apurímac y Madre de Dios \\
\hline
\end{tabular}

También se ha establecido una zona o área virtual, que se encuentra reservada para la telefonía móvil y que podrá implementarse cuando las necesidades del mercado y/o la Administración lo consideren pertinente.

Finalmente, el PTFN ha establecido los procedimientos que se siguen para la marcación y acceso a los servicios de telecomunicaciones. Por medio

Prefijo internacional: por preselección, de llamada por llamada; prefijo de larga distancia nacional: por preselección, llamada por llamada; prefijo para el acceso a facilidades de red inteligente. 
de dichos procedimientos, se combinan las diferentes estructuras de numeración a las que hemos hecho referencia.

\section{De la gestión y supervisión de la numeración}

\section{1. Ámbito de aplicación}

Los operadores o concesionarios de servicios públicos de telecomunicaciones, los titulares de servicios de valor añadido y los comercializadores de servicios de telecomunicaciones están sujetos al marco reglamentario de gestión y supervisión de los recursos de numeración, aprobado por el legislador peruano. ${ }^{97}$

Como regla general, en caso de asignación de numeración, los titulares están obligados a garantizar que sus planes de numeración estén enmarcados en el PTFN.

\section{2. Ámbito institucional}

Desde un punto de vista institucional, los órganos que ejercen competencias de tipo administrativo en la gestión y supervisión de la utilización del recurso de numeración son los siguientes:

- la Dirección de Gestión del MTC, como órgano encargado de la atención y resolución de solicitudes de asignación de numeración que se presenten, así como para dejar sin efecto la asignación, disponer la reversión del recurso numérico y absolver las consultas relativas a la gestión de la numeración;

- la Dirección de Control del MTC, como órgano a cargo de la supervisión del cumplimiento de las obligaciones y las condiciones específicas establecidas para la utilización de la numeración asignada; y

- la Secretaría de Telecomunicaciones del MTC, como órgano a cargo de evaluar y proponer las modificaciones al PTFN, así como también la definición de los servicios especiales con interoperabilidad. ${ }^{98}$

$97 \quad$ Al respecto, véase el artículo 1 del Reglamento para la Gestión y Supervisión de la Numeración de los Servicios Públicos de Telecomunicaciones, que fue aprobado vía el decreto supremo 021-2004-MTC, de 22 de abril de 2004.

98 Al respecto, véanse los artículos 2 y 4 del decreto supremo 021-2004-MTC. 


\subsection{Principios y criterios aplicables a la asignación}

En relación con los principios aplicables, ${ }^{99}$ la norma establece que, durante la realización del proceso de asignación, tendrá que observarse los siguientes principios: eficiencia, que debe considerar la satisfacción de la demanda de los usuarios; igualdad de oportunidades e imparcialidad; y transparencia.

Estrechamente vinculados con los principios antes enunciados, los criterios que se denben tomar en cuenta son la asignación eficiente, la disponibilidad de la numeración, y la utilización del registro asignado de acuerdo con el plan previsto.

Complementariamente, se tendrán en cuenta los siguientes aspectos: la asignación de un código único por concesionario, el mantenimiento del mismo código de concesionario en el caso de servicios especiales con interoperabilidad y la utilización de sorteos en caso de coincidencia en la solicitud de un mismo número.

Finalmente, el MTC, en la medida de lo posible, establecerá los rangos de numeración diferenciados por los servicios públicos de telecomunicaciones, así como de identificación de los concesionarios que los prestan.

\section{Procedimiento para la asignación de la numeración y causales para de- jarla sin efecto}

El procedimiento de asignación establecido por el reglamento se inicia con la presentación de una solicitud por el operador concesionario, quien deberá describir el plan de numeración y/o el servicio por utilizar; la justificación del recurso solicitado; y cuál va a ser su uso, detallando los servicios o facilidades que se van a prestar. ${ }^{100}$ En el supuesto concreto de que la solicitud esté dirigida a la obtención del código de numeración de servicios especiales con interoperabilidad, ${ }^{101}$ esta se encuentra sujeta a las siguientes condiciones: que se verifique que la peticionante ya ha iniciado la prestación comercial del servicio telefónico fijo otorgado en concesión y que se amplíen planes mínimos de expansión. ${ }^{102}$

\footnotetext{
99 Al respecto, véase el artículo 5 del decreto supremo 021-2004-MTC.

100 Al respecto, véase el artículo 6 del decreto supremo 021-2004-MTC.

101 Los servicios especiales con iterporalidad son definidos por el PTFN como aquellos servicios especiales brindados por los concesionarios de los servicios públicos locales, que deben ser necesariamente reconocidos por todas las redes de los demás concesionarios de los servicios públicos locales. Por ejemplo, se consideran servicios de este tipo las tarjetas prepago para llamadas locales e internacionales. Con respecto a estos servicios, se ha dictado el decreto supremo 062-2003-MTC, en el que se busca precisar sus alcances.

102 Al respecto, véase el artículo 22 del decreto supremo 021-2004-MTC.
} 
Por otro lado, el legislador peruano ha establecido una serie de supuestos que implica que se deje sin efecto, de forma parcial o total, la asignación del recurso de numeración, de tal forma que, de producirse estos, los recursos revertirán al Estado. ${ }^{103}$ En caso de dejar sin efecto parcialmente la asignación, esta procederá si el operador así lo ha solicitado o si se ha establecido que el operador precisa de menos recursos de numeración que los asignados. Sobre este segundo supuesto, es necesario tener presente que, de forma previa, se tiene que haber realizado una supervisión de la autoridad sectorial, de manera que pueda garantizarse la legalidad de la resolución administrativa.

En caso de que se disponga dejar sin efecto totalmente la asignación, esta podrá producirse en los siguientes supuestos:

- Si es que el operador así lo ha solicitado, se ha incumplido con las obligaciones de los operadores y con las condiciones específicas para la utilización asignada.

- La utilización del recurso sea manifiestamente insuficiente, se incumplan las normas sobre servicios especiales con interoperabilidad.

- Se resuelva o termine el contrato de concesión del operador.

- Se cancele la inscripción.

\section{Derechos y obligaciones de los titulares de la numeración}

Con relación a los derechos que corresponden a los operadores a los cuales les ha sido asignada numeración, la legislación ha considerado los siguientes: ${ }^{104}$

- el uso y administración del recurso numérico asignado;

- la potestad de transferir el recurso numérico asignado, previa aprobación del MTC; y

- otros aspectos que pueda determinar el MTC mediante resolución ministerial.

En el caso de transferencia del recurso de numeración, conforme lo dispone la norma reglamentaria, deberá seguirse un procedimiento para conseguir el pronunciamiento en que el MTC autorice dicha operación. ${ }^{105}$ En

\footnotetext{
103 Al respecto, véase el artículo 18 del decreto supremo 021-2004-MTC.

104 Al respecto, véase el artículo 10 del decreto supremo 021-2004-MTC.

105 Al respecto, véase el artículo 17 del decreto supremo 021-2004-MTC.
} 
nuestra opinión, dicha solicitud no debe tener el carácter de mero trámite, sino que debe ser analizada detenidamente por la autoridad sectorial, ya que puede llevar a que se genere todo un tráfico especulativo de dicho recurso, lo que perjudicaría las condiciones de competencia en el mercado en lo que a oferta de servicios se refiere.

En lo que respecta a las obligaciones de los operadores con relación a los recursos de numeración que le han sido asignados, puede distinguirse una serie de obligaciones generales de aquellas otras de carácter específico.

Obligaciones generales: ${ }^{106}$

- Usar el recurso asignado de acuerdo con los fines especificados en la resolución administrativa.

- Iniciar la utilización de la numeración asignada en un plazo no mayor de 12 meses, que se cuentan desde la fecha de notificación de la respectiva resolución.

- Contar y poner a disposición de las Direcciones de Gestión y Control un registro actualizado que contenga el uso del recurso numérico asignado.

\section{Obligaciones especificas:}

- Cumplir con aquellas condiciones específicas para el uso de la numeración que imponga la Dirección de Gestión a efectos de dar cumplimiento al PTFN. ${ }^{107}$

- Facilitar los números a sus abonados, suscriptores y comercializadores, de ser el caso. ${ }^{108}$

- Informar a los operadores con los que se encuentran interconectados (nacionales e internacionales) la nueva numeración asignada por el MTC. ${ }^{109}$

- Remitir información a la Dirección de Gestión del MTC durante el mes de enero de cada año y siempre que hayan transcurrido más de seis meses desde la fecha de la resolución de asignación del recurso sobre las previsiones de utilización de la numeración para el año en curso, así como la relativa al año precedente. ${ }^{110}$

\footnotetext{
106 Al respecto, véase el artículo 11 del decreto supremo 021-2004-MTC.

107 Al respecto, véase el artículo 12 del decreto supremo 021-2004-MTC.

108 Al respecto, véase el artículo 13 del decreto supremo 021-2004-MTC.

109 Al respecto, véase el artículo 14 del decreto supremo 021-2004-MTC.

110 Al respecto, véase el artículo 15 del decreto supremo 021-2004-MTC.
} 
- En caso de modificación de las condiciones especificadas para la utilización de la numeración, el operador deberá solicitar autorización a la Dirección de Gestión. ${ }^{11}$

Es importante, a efectos de supervisión, el cumplimiento de la obligación de remitir información a la Dirección de Gestión, ya que dicha autoridad sectorial podrá establecer si el operador utiliza de forma eficiente el recurso y si no realiza reservas del mismo que puedan perjudicar a los otros operadores de servicios similares. ${ }^{112}$

\section{La portabilidad numérica}

La LTel, el RTel y el Reglamento para la Gestión y Administración de Recurso de Numeración no han previsto la regulación de aquellos aspectos que tienen que ver con la portabilidad numérica. Sin embargo, de la interpretación del artículo $73^{113}$ de la LTel, puede colegirse que el derecho de elección del usuario/abonado está directamente vinculado con el derecho a la portabilidad numérica, ya que, precisamente en el ejercicio del derecho de elección, puede cambiarse de operador de los servicios de telecomunicaciones conservando el número que le fuera asignado. Además, la citada norma establece la prohibición general de que los operadores de servicios realicen prácticas que impidan o distorsionen el derecho del usuario a la libre elección.

Si nos atenemos a la naturaleza jurídica de la numeración, se puede admitir que esta no tiene la consideración de derecho o interés patrimonial legítimo de los operadores de servicios públicos de telecomunicaciones, de ahí que no sea expropiable, ni que sobre ella se proyecte derecho real alguno de propiedad industrial o intelectual de los operadores ni que pueda ser libremente transferida, salvo si el MTC lo autoriza. ${ }^{114}$

La no apropiabilidad del recurso de numeración por los operadores implica, para el abonado, el derecho de conservación de los números que les han sido asignados, de modo que podrán cambiar de operador del servicio

\footnotetext{
111 Al respecto, véase el artículo 16 del decreto supremo 021-2004-MTC.

112 Al respecto, véase el artículo 24 del decreto supremo 021-2004-MTC.

113 Al respecto, el artículo 73 de la LTel dispone:

"Artículo 73.- El usuario, en la medida que sea técnicamente factible tiene derecho de elegir el operador del servicio de telecomunicaciones que a su criterio le convenga. En este sentido las empresas que presten servicios de telecomunicaciones se abstendrán de realizar prácticas que impidan o distorsionen el derecho del usuario a la libre elección».

114 Seguimos el planteamiento de SÁnCHez RodRíGuez, A. J. Op. cit., p. 120.
} 
público de telecomunicaciones cuantas veces estimen y sea técnicamente posible; así, los operadores tienen la obligación de transferir el número al operador libremente seleccionado por el usuario. ${ }^{115}$

De acuerdo entonces con lo sostenido, la portabilidad se entiende como el derecho de los abonados a un servicio público de telecomunicaciones a conservar su número cuando cambian de operador.

El cambio de número puede ocasionar tales perjuicios al abonado que incluso puede llegar a hacerle desistir de cualquier intento; de esta forma, este renuncia a las nuevas condiciones que le pudiese ofrecer otro operador. Sin embargo, el problema de fondo es que se crea una situación que puede llegar a dificultar la libre competencia y la libertad de elección del operador concesionario y que carece de justificación cuando no hay limitaciones técnicas para realizar la operación. ${ }^{116}$

Por ello, fundamentalmente, con el objetivo de tomar la decisión de cambiar de operador sobre la base de consideraciones relacionadas exclusivamente con el servicio (técnicas y/o económicas) y no por los perjuicios que pudiera ocasionarle el cambio de número, se introduce la figura de la portabilidad numérica como medida liberalizadora del reconocimiento del derecho a conservar el número al abonado.

Es claro, entonces, que la conservación del número se ha revelado como una cuestión importante desde la perspectiva de la promoción de la competencia, de ahí que la exigencia se haya ido introduciendo en todos los países. ${ }^{117}$

En España, la ley 32/2003 ha regulado la portabilidad en el artículo $18,{ }^{118}$ intitulándola como "Conservación de los números telefónicos por sus usuarios». Asimismo, en el ámbito de la Unión Europea, la Directiva

115 Ib., loc. cit. Como precisa FERnANDO PABLO, M. M. Derecho General de las Telecomunicaciones. Madrid: Colex, 1998, p. 87; este derecho "se traduce en la obligación de los operadores de redes públicas y de servicios abiertos al público de facilitar tal conservación, mediante una suerte de "tráfico de números», en el que es el abonado el que aminora o incrementa los números asignados a cada operadora, si bien una vez que cesa en abono a una operadora, ésta pierde el derecho a explotar dicho número».

116 Al respecto, véase GRETEL. Competencia y regulación en los mercados de telecomunicaciones, el audiovisual e Internet. Op. cit., p. 250; CONTRERAS, L. "Portabilidad de número de abonado en redes actuales y futuras». En VII Jornadas Telecom I+D, 28-29 de octubre de 1998, Madrid; y MONTERO, J. J. y H. BROKELMANN. Op. cit., p. 349; entre otros.

117 LaGuna de PAZ, J.C. Op. cit., pág. 130.

118 Al respecto, véase el comentario que de este artículo realiza CREMADES, J. "Conservación de los números telefónicos por los abonados». En J. Cremades u J. Rodriguez-Arana (dirs.) Op. cit., p. 293 y ss.; y el estudio sobre la materia de portabilidad de FERNANDEZARAGONCIllo, M. En J. M. Villar Uríbarri (dir.). Op. cit., p. 115 y ss. 
Servicio Universal ha regulado esta materia, incidiendo en que es extensible «a todos los abonados a servicios telefónicos disponibles al público incluidos los servicios de telefonía móvil ${ }^{119}$ con independencia de la empresa que preste el servicio en una ubicación geográfica (números geográficos) o en cualquier ubicación (números no geográficos).

Como señalamos, en el Perú aún no se regulado la portabilidad. A la fecha, solo existe un comité liderado por el MTC que está evaluándola; además, recientemente se ha hecho público un «Estudio Relacionado con la implementación de la Portabilidad Numérica», ${ }^{120}$ en el cual destacan:

- la definición de portabilidad dentro de los parámetros antes señalados;

- los tipos de portabilidad que pueden darse (del proveedor de servicios, de servicio y geográfica);

- la identificación de los beneficios que representa, entre los que destacan el referido a la libertad de elección del abonado con respecto al proveedor de servicios, así como el de la promoción de la competencia;

- las pautas para su implementación (procedimientos simples, bajo costo, plazos breves, intervalos razonables al momento de portar, razones válidas para impedir la portabilidad, números por portar por abonado), así como los aspectos que deben garantizarse (flexibilidad de arquitectura, transparencia, calidad de funcionamiento e interconexión);

- las técnicas de implementación de la portabilidad más comunes, sus ventajas y desventajas y la técnica que debe ser implementada;

- los impactos usuales en la red;

- los costos generales de la portabilidad numérica y un análisis de la demanda del servicio;

- las acciones para implementar la portabilidad numérica.

De acuerdo con el referido informe, el tipo de portabilidad más adecuado para el grado de desarrollo del servicio de telecomunicaciones que debe implementarse sería el de Portabilidad del Proveedor de Servicios, denominado «Portabilidad del Número Local». De esta forma, corresponderá al MTC establecer en qué casos la portabilidad será aplicable, ya sea por el cambio de operador del servicio de telefonía pública fija (pudiendo establecerse restricciones cuando el cambio implique la modificación del servicio o cuando el cambio de ubicación física afecte la zona de numeración y la

\footnotetext{
119 Al respecto, véase. el artículo 30 de la Directiva Servicio Universal y los comentarios al mismo que realizan NiHOUL P. y P. RODFORD. Op. cit., pp. 742-744.

120 El informe esta disponible en <http://www.mtc.gob.pe/novedades/pdf/Portabilidad_ Numerica.pdfs (4 de diciembre de 2004).
} 
cobertura geográfica de la misma), o por el cambio de operador de servicios de telefonía móvil.

Sobre esto último, el informe se inclina porque la portabilidad numérica sea implementada en las redes de telefonía fija y plantea como una posibilidad el hecho de que también lo sea en caso de telefonía móvil. Al respecto, consideramos que, si la portabilidad es implementada, debería hacerse en ambos tipos de servicios (fijo y móvil), porque el crecimiento del mercado de telefonía móvil en el Perú es gradual y progresivo, ${ }^{121}$ porque hay una importante utilización personal y comercial del servicio y porque este es un sector en el cual hay mayor movilidad de los abonados (particulares y empresas) con respecto a las ofertas de servicios que hacen los operadores.

Finalmente, es necesario tener presente la importancia de la pauta de implementación de la portabilidad mencionada en el informe, referida a que deben diseñarse procedimientos simples y con plazos y condiciones adecuados, porque, si ello no fuera así, a la luz de la experiencia en otro países, la portabilidad se convertiría en un verdadero cuello de botella (bottle neck) en el mercado de servicios de telecomunicaciones, con los perjuicios que ello acarrearía tanto al abonado como a la competencia entre operadores.

121 Al respecto, véanse las cifras del crecimiento del mercado de telefonía móvil expuesta recientemente por OSIPTEL y que están disponibles en http://www.osiptel.gob.pe/ 